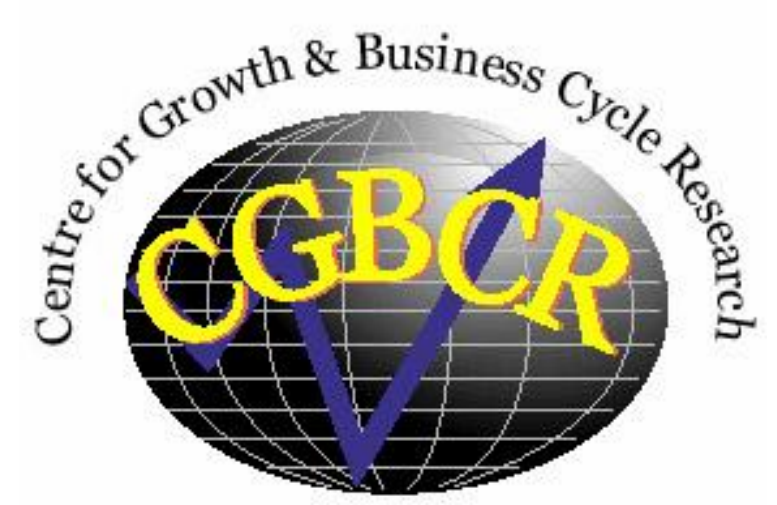

Discussion Paper Series

\title{
Spillovers and Correlations between US and Major European Stock Markets: The Role of the Euro
} By

\author{
Christos S. Savva, Denise R. Osborn and Len Gill
}

Centre for Growth and Business Cycle Research, Economic Studies, University of Manchester, Manchester, M13 9PL, UK

November 2005

Number 064

Download paper from:

http://www.ses.man.ac.uk/cgbcr/discussi.htm 


\title{
Spillovers and Correlations between US and Major European Stock Markets: The Role of the Euro
}

\author{
Christos S. Savva, Denise R. Osborn and Len Gill \\ University of Manchester
}

\begin{abstract}
This paper investigates the transmission of price and volatility spillovers across the New York, London, Frankfurt and Paris stock markets under the framework of the multivariate EGARCH model. The model is extended to allow dynamic conditional correlations, with the correlations allowed to change with the introduction of the Euro. By using daily closing prices recorded at 16:00 London time (pseudo-closing prices) we find evidence that domestic stock returns and volatilities are influenced by the behavior of foreign markets, with both volatilities and conditional correlations responding asymmetrically to news/innovations in other markets. The findings also indicate that the correlations of returns have increased for all markets since the launch of the Euro, with that between Frankfurt and Paris experiencing the largest increase.
\end{abstract}

JEL Classification: C32; F36; G15.

Keywords: Stock Returns; Introduction of Euro; Multivariate EGARCH Model; Volatility Spillovers; Dynamic Conditional Correlation.

Corresponding author:

Christos Savva

Economic Studies, School of Social Sciences

University of Manchester

Manchester M13 9PL, UK

Tel.:+44-161-275-4866

Fax: +44-161-275-4928

Email: christos.savva-1@postgrad.man.ac.uk

We are very grateful to Ralf Becker, Maria Kasch-Haroutounian, Dick Van Dijk, and to participants at the Journal of Applied Econometrics Conference in Venice 2005, for their helpful comments and suggestions. We are also indebted to Olan Henry for providing the Gauss codes which were modified and used for computing the News Impact Surfaces. 


\section{Introduction}

In the period of globalization, the transmission of effects across international financial markets is an issue of great interest for investors and policy makers. It is well known, and consistent with the efficient market hypothesis, that stock traders incorporate into their decisions not only information generated domestically, but also information from stock markets in other countries. Policymakers are interested in financial markets due to the effect wealth has on the decisions made by economic agents, and it is sometimes argued that financial markets provide a key link in increasing international economic integration (for example, Koutmos and Booth, 1995). For these reasons, the extent of linkages across stock markets in different countries has been an important topic in recent research.

Initially, these studies focused primarily on the interaction and interdependence of stock markets in terms of the distribution of observed returns. For example, Grubel (1968) examines the comovements and correlations between different markets and investigates the gains of international diversification from a US perspective. However, more recent studies investigate interactions in terms of the volatilities, in addition to the values, of returns. The general finding of this literature is that asymmetric volatility spillovers exist between major stock markets, so that volatility increases, induced by "bad news", are transmitted more strongly than volatility declines (Hamao, Masulis, and Ng, 1990, Koutmos et al., 1995, Koutmos, 1996), Antoniou, Pescetto and Violaris, 2003, Veiga and McAleer, 2003).

A number of these studies examine linkages among European markets, or between European and US markets. One reason for this interest is that the international flow of funds reveal that the European stock markets are now the most important destinations of international equity capital, dominating the leadership that the US and Japanese markets experienced in previous periods (Antoniou et .al., 2003). Perhaps more importantly, 
increasing economic integration in Europe has led researchers to question whether financial markets have responded by also becoming more integrated. Arguably the introduction of the common Euro currency in January 1999, with the European Central Bank having responsibility for monetary policy in the Euro Area, represents the most dramatic step to date in European economic integration, so that the impact of this particular event on European financial markets has become a specific focus of recent research. Furthermore, the Euro removes the potentially important uncertainty connected with exchange rate fluctuations, and hence should reduce uncertainties concerned with stock market investments across country borders within the Euro Area.

A number of different approaches have been taken in previous studies. For instance, Melle (2003) uses a VAR analysis to show that European stock markets are more integrated after the introduction of the Euro, with the German stock exchange becoming the leader for other European markets. However, the VAR framework is not able to capture volatility spillovers or possibly time-varying correlations in the shocks affecting these markets.

Cheung and Westermann (2001) examine the relationship between German and US equity markets separately for periods before and after the introduction of the Euro, finding that volatility persistence of the German stock index has fallen significantly, compared to the US index, but that the causality pattern has not changed. However, the lower volatility for Germany after the introduction of Euro is not in line with the results of Billio and Pelizzon (2003), who conclude that volatility for Germany increases after the Euro. Billio and Pelizzon (2003) and Baele (forthcoming) adopt stochastic regime-switching frameworks to investigate effects associated with the Euro, with the latter examining how US and aggregate European volatility spills over into various European stock markets. Christiansen $(2003,2005)$ finds that the introduction of Euro is associated with a structural break, and 
also concludes that significant volatility spillovers are transmitted from aggregate US and European bond and stock markets into national European markets.

All of the above studies are, however, limited in that they make the implicit assumption that the correlations of shocks affecting markets are unchanged over the subperiods examined. The validity of this assumption is questionable, especially in the context of increasing economic co-operation between European countries. In an important study, Capiello et. al. (2003) relax this assumption, by adopting the Dynamic Conditional Correlation (DCC) model and they uncover evidence that the correlations between Euro countries increase after the introduction of the Euro. Taylor et. al. (2005), under a timevarying copula model, confirm these results in relation to large European equity markets. In a recent study, Kim et. al. (forthcoming) find an increase in stock markets' returns correlations of all countries of the European Monetary Union (EMU) with a weighted EMU index and, further, that the introduction of Euro has strengthened European volatility linkages.

Despite the substantial number of studies of stock market interdependence that focus on the impact of the Euro on European markets and their correlations, it is surprising that most of these studies neglect the effects from the returns in other markets, with the omission of the US being particularly notable. Further, even aside from the effects of the Euro, there is evidence that stock returns across national markets exhibit time-varying correlations (for instance, see Tse, 2000). Few studies adopt such a framework. However, those that do so ignore volatility spillovers, which may also be important.

A further limitation of most of the aforementioned studies is their use of weekly prices, which limits the ability of the models to capture multivariate dynamics. Where daily data are used, they are closing prices. However, time zones differ even across the Euro 
Area, so that these conflate spillovers and contemporaneous correlations, while the use of closing prices underestimates the conditional correlation (Marten and Poon, 2001). To overcome those difficulties, we use daily closing prices recorded at a common time, namely 16:00 London time, which are referred to as pseudo-closing prices.

The present paper investigates the relationships between the major European stock markets alongside the US market. The US market is included not simply to represent nonEuropean markets, but also because the US is the largest economy in the world and many of the world's largest companies are based in the US. The major European markets included are those of the UK, Germany and France, with the last two being the foremost markets within the Euro Area. A novel feature of this study is to allow for spillovers in both returns and volatility across international financial markets using pseudo-closing prices. Further, we not only use a DCC model to capture time-varying correlations, but we also test whether the underlying unconditional correlations change at the introduction of the Euro.

The paper is organized as follows: Section 2 discusses the methodological design of the study; while Section 3 contains the substantive results. Section 4 summarizes the study and concludes. 


\section{Methodology}

We use a dynamic conditional correlation (DCC) form of the multivariate EGARCH model to investigate market interdependence and volatility transmission between stock markets in different countries. The EGARCH model is used as a framework to take account of asymmetric volatility spillovers, whose presence is now well established (Hamao, Masulis, and Ng, 1990, Koutmos et al., 1995, Koutmos, 1996, Antoniou, Pescetto and Violaris, 2003, Veiga and McAleer, 2003). However, whereas the standard multivariate EGARCH model assumes that the underlying correlations between shocks are constant over time, we allow these to be time-varying. The DCC model was proposed by Engle (2002), but the formulation he uses does not take account of volatility spillovers. Within this general framework, we investigate whether the introduction of the Euro altered the relationships between European stock markets.

For $n$ stock markets, dynamic relationships in returns are captured using a Vector Autoregressive (VAR) model

$$
Y_{i t}=\beta_{i 0}+\sum_{j=1}^{n} \beta_{i j} Y_{j, t-1}+\varepsilon_{i t}
$$

so that the conditional mean return in each market, $E\left[Y_{i t} \mid \xi_{t-1}\right]$, where $\xi_{t-1}$ is the information set containing all historic returns, is a function of own past returns and cross-market past returns. A first-order VAR is adopted since we anticipate that stock markets will quickly respond to information from other markets.

Following Koutmos and Booth (1995), Antoniou et. al. (2003) among others, we model the conditional variances according to the multivariate EGARCH model: 


$$
\begin{aligned}
& \sigma_{i, t}^{2}=\exp \left[\alpha_{i, 0}+\sum_{j=1}^{n} \alpha_{i, j} f_{j}\left(z_{j, t-1}\right)+\delta_{i} \ln \left(\sigma_{i, t-1}^{2}\right)\right] \\
& f_{j}\left(z_{j, t-1}\right)=\left(\left|z_{j, t-1}\right|-E\left(\left|z_{j, t-1}\right|\right)+\gamma_{j} z_{j, t-1}\right)
\end{aligned}
$$

so that the conditional variance in each market is an exponential function of past standardized innovations $\left(z_{j, t-1}=\varepsilon_{j, t-1} / \sigma_{j, t-1}\right)$. Persistence in volatility is measured by $\delta_{i}$, with the unconditional variance being finite if $\delta_{i}<1$ (Nelson, 1991). Spillovers are captured by the coefficients $\alpha_{i, j}(j \neq i)$, while asymmetry implies negative $\gamma_{j}$. Therefore, a statistically significant positive $\alpha_{i, j}$ in (2) coupled with a negative (positive) $\gamma_{j}$ in (3) implies that negative innovations in market $j$ have a greater impact on the volatility of market $i$ than positive (negative) innovations. The relative importance of the asymmetry (or leverage effect) can be measured by the ratio $\left|-1+\gamma_{\mathrm{j}}\right| /\left(1+\gamma_{\mathrm{j}}\right)$. Finally, $\left|z_{j, t}\right|-E\left(\left|z_{j, t}\right|\right)$ measures the size effect. Assuming positive $\alpha_{i, j}$, the impact of $z_{j, t}$ on $\sigma_{i, t}^{2}$ will be positive (negative) if the magnitude of $z_{j, t}$ is greater (smaller) than its expected value $E\left(\left|z_{j, t}\right|\right.$ ). Moreover, the EGARCH model does not need parameter restrictions to ensure positive variances.

The disturbances of (1) are assumed to be conditionally multivariate normal with mean zero and conditional covariance matrix $H_{t}$ :

$$
\varepsilon_{t} \mid \xi_{t-1} \sim N\left(0, H_{t}\right)
$$

and

$$
H_{t}=D_{t} P_{t} D_{t} \text { or } \sigma_{\mathrm{ij}, \mathrm{t}}=p_{i j, t} \sigma_{i, t} \sigma_{j, t}
$$

This assumption of conditional normality is made only to motivate the usual of quasimaximum likelihood estimation of the parameters; non-normality is allowed for by using robust "sandwich" standard errors for the parameter estimates. In (5), $D_{t}$ is a $n \times n$ diagonal 
matrix with the time-varying standard deviations of (3) on the diagonal and $P_{t}$ is a timevarying symmetric correlation matrix:

$$
D_{t}=\left[\begin{array}{cccc}
\sigma_{1, t} & 0 & \ldots & 0 \\
0 & \sigma_{2, t} & & 0 \\
\cdot & & \cdot & \cdot \\
\cdot & & \cdot & \cdot \\
0 & 0 & \ldots & \sigma_{n, t}
\end{array}\right], P_{t}=\left[\begin{array}{cccc}
p_{1,1, t} & p_{1,2, t} & \cdots & p_{1, n, t} \\
p_{2,1, t} & p_{2,2, t} & & p_{2, n, t} \\
\cdot & & \cdot & \cdot \\
\cdot & & & \cdot \\
p_{n, 1, t} & p_{n, 2, t} & \cdots & p_{n, n, t}
\end{array}\right]
$$

The key to the DCC model is the specification of the dynamic correlation matrix $P_{t}$.

Except for scaling, considered below, the dynamic correlations are captured in our model through the asymmetric general diagonal DCC equation (hereafter AGDCC):

$$
\begin{aligned}
Q_{t}= & \left(\bar{Q}-A^{\prime} \bar{Q} A-B^{\prime} \bar{Q} B-C^{\prime} \bar{N} C\right)+ \\
& A^{\prime} z_{t-1} z_{t-1}{ }^{\prime} A+B^{\prime} Q_{t-1} B+C^{\prime} \eta_{t-1} \eta_{t-1}{ }^{\prime} C
\end{aligned}
$$

with $\bar{Q}$ and $\bar{N}$ being the unconditional correlation matrices of $z_{t}$ and $\eta_{t}$, with $\eta_{i, t}=I_{\left[z_{i, t}<0\right]} z_{i, t}$, where $I_{\left[z_{i, t}<0\right]}$ is the indicator function which takes the value unity when $z_{i, t}<0$. This model is a generalization of the DCC model of Engle (2002) to capture asymmetric correlations and was first used by Capiello et al. (2003). For our purposes $A, B$ and $C$ are defined to be $n \times n$ diagonal matrices ${ }^{1} . Q_{t}$ is positive definite with probability one if $\left(\bar{Q}-A^{\prime} \bar{Q} A-B^{\prime} \bar{Q} B-C^{\prime} \bar{N} C\right)$ is positive definite. Through the final term of (7), the timevarying correlations can respond asymmetrically to positive or negative shocks in each market.

Because $Q_{t}$ in (7) does not have unit diagonal elements, we scale it to get a proper correlation matrix $P_{t}$ :

\footnotetext{
${ }^{1}$ In principle, these matrices do not have to be diagonal. However, they are restricted to being diagonal for practicality in the estimation of our models.
} 


$$
P_{t}=Q_{t}^{*-1} Q_{t} Q_{t}^{*-1} \text {. }
$$

The multivariate EGARCH specification of $(2) /(3)$ is a rich one, allowing us to examine both volatility spillovers between markets and asymmetries. It is, however, not useful to apply such an EGARCH specification of this form to the conditional correlations, both because it would unduly restrict the conditional correlations to be always positive and because it has too many parameters. The DCC specification of (6) does not have these problems, but nevertheless allows the possibility of asymmetric effects.

Although an extensive literature exists documenting asymmetries in volatility, it is a novel question in terms of conditional correlations. However, Cappiello et al. (2003) point out that the correlation may be higher after negative shocks to two assets than positive shocks of the same magnitude, due to the effects of higher risk.

Despite the generality of (1)-(8), it may not be sufficiently general to capture the effects of increasing integration of shocks across some markets after the introduction of the Euro. In particular, the AGDCC specification of (7) implicitly assumes constant unconditional correlation matrices for $z_{t}$ and $\eta_{t}$, represented $\bar{Q}$ and $\bar{N}$, whereas these may alter consequent upon the potential structural break, represented by the introduction of the Euro.

To include the structural break in the correlation equation, following van Dijk et al. (2005), we define sub-period unconditional correlation matrices

$$
\begin{aligned}
& \bar{Q}=Q_{1} I[t<\tau]+Q_{2} I[t \geq \tau] \\
& \bar{N}=N_{1} I[t<\tau]+N_{2} I[t \geq \tau]
\end{aligned}
$$

where $I\left[\right.$.] is the indicator function and $\tau$ denotes the break point, while the matrices $Q_{1}, Q_{2}$, $N_{1}$, and $N_{2}$ are unconditional correlation matrices of $z_{t}$ and $\eta_{t}$, respectively, over the relevant sub-periods. Then (7) can be generalized to 


$$
\begin{array}{r}
Q_{t}=\left(\bar{Q}_{1}-A^{\prime} \bar{Q}_{1} A-B^{\prime} \bar{Q}_{1} B-C^{\prime} \bar{N}_{1} C\right)+\left(\bar{Q}_{2}-A^{\prime} \bar{Q}_{2} A-B^{\prime} \bar{Q}_{2} B-C^{\prime} \bar{N}_{2} C\right) \\
+A^{\prime} z_{t-1} z_{t-1}{ }^{\prime} A+B^{\prime} Q_{t-1} B+C^{\prime} \eta_{t-1} \eta_{t-1}{ }^{\prime} C
\end{array}
$$

The model is estimated by maximum likelihood. As $\varepsilon_{t} \mid \xi_{t-1}$ is normally distributed, the log likelihood can be expressed as:

$$
\begin{aligned}
L & =-\frac{1}{2} \sum_{t=1}^{T}\left(n \log (2 \pi)+\log \left|H_{t}\right|+\varepsilon_{t}{ }^{\prime} H_{t}^{-1} \varepsilon_{t}\right) \\
& =-\frac{1}{2} \sum_{t=1}^{T}\left(n \log (2 \pi)+\log \left|D_{t} P_{t} D_{t}\right|+\varepsilon_{t}{ }^{\prime}\left(D_{t} P_{t} D_{t}\right)^{-1} \varepsilon_{t}\right)
\end{aligned}
$$

which can be maximized over the parameters of the model. Of course, if the normality assumption is violated, the estimates become pseudo-maximum likelihood ones. Although Engle (2002) and Cappiello et al. (2003) use a two step approach, Wong and Vlaar (2003) show this can lead to a relatively large loss of efficiency and we estimate the complete model of (1)-(8), using (7) or ( $\left.7^{\prime}\right)$, in a single step. This is feasible since our application relates to four markets. All computations are carried out using GAUSS.

At this point it is worth noting how our model differs from that of Capiello et al. (2003). Firstly, by including the lagged returns from each market in the mean equation, we are able to capture the price spillover effects from one market to another. Similarly, we capture the volatility spillover effects in (2), while also capturing asymmetry. However, covariances are modeled in a similar way to Capiello et al. Nevertheless, since they do not consider spillovers in returns or volatility, their model may incorrectly attribute any spillovers to the conditional correlations. Finally, we use a one-step estimation procedure, which is more efficient estimation than their two-step approach. In addition, by using a onestep estimation procedure, it is easier to calculate the robust quasi-maximum likelihood (QML) standard errors. 
Our model is also more general than that employed by Kim et al. (forthcoming). Their analysis is bivariate, examining the relationship between individual markets and an overall Euro Area index, and hence does not examine interactions between individual markets. Further, their dynamic conditional correlation model is more restrictive, particularly in not allowing for possible asymmetries, which is one of the features of our analysis.

\section{$\underline{\text { 3. Empirical Results }}$}

\subsection{Data and preliminary statistics}

Our data consist of daily prices recorded at 16:00 London time (pseudo-closing prices) of S\&P-500 (USA), FTSE-100 (UK), DAX-30 (Germany), and CAC-40 (France) indices, which are designed to reflect the largest firms in the respective markets ${ }^{2}$. We use 16:00 London time closing prices in order to avoid the problems of non-synchronous data, which conflates correlation effects and spillovers (see Martens and Poon, 2001). The period is December 3, 1990 to August 6, 2004³. Since the data come from different countries, different holidays apply for each market. We side-step this problem by taking the holiday (pseudo) closing price as being the same as the previous day. Hence the sample for each country contains all days of the week except weekends.

\footnotetext{
${ }^{2}$ The DAX-30 is a price-weighted index of the 30 most heavily traded stocks in the German market, while the FTSE-100 consists of the largest 100 UK companies by full market value. CAC-40 is calculated on the basis of 40 best French titles, listed on the Paris Bourse. Finally S\&P-500 is a value weighted index representing approximately 75 percent of total US market capitalization.

${ }^{3}$ This was the longest series available when the data were collected.
} 
Although some analyses, including Capiello et al. (2003) use weekly data, we prefer to use daily data (especially pseudo-closing prices) because market efficiency suggests that news is quickly incorporated into stock prices. Thus, lower frequency data may be unable to capture many forms of market spillovers, including how the "psychology" is transmitted from one market to another (Veiga et al., 2003).

We analyze returns, defined as the difference of the logarithm of the price index, scaled by 100 . This scaling approximates percentage changes and helps to avoid convergence problems in estimation.

Figure 1 plots the logs of the raw series (with vertical lines indicating the introduction of the Euro on 1 January 1999), while Table 1 reports summary statistics for the daily returns of the four markets. Average returns are positive for all markets, with New York possessing the highest value followed by Frankfurt. All return series are negatively skewed (except for London) and highly leptokurtic with respect to the normal distribution. Likewise the Kolmogorov-Smirnov (KS) statistic and Jarque-Bera (JB) test reject normality for each of the return series at least at 5 percent level of significance. The Ljung-Box (LB) statistic for up to 12 lags, for returns and squared returns, indicate the presence of linear and non-linear dependencies, respectively, in the returns of all four markets. Linear dependencies may be due to some form of market inefficiency while non-linear dependence may be due to autoregressive conditional heteroskedasticity. Furthermore, the LB statistic for the squared returns is, in all cases, several times that calculated for returns, indicating that second moment (nonlinear) dependencies are far more significant than first moment dependencies (Koutmos, 1996). 
Figure 1. Plots of the Price Indices

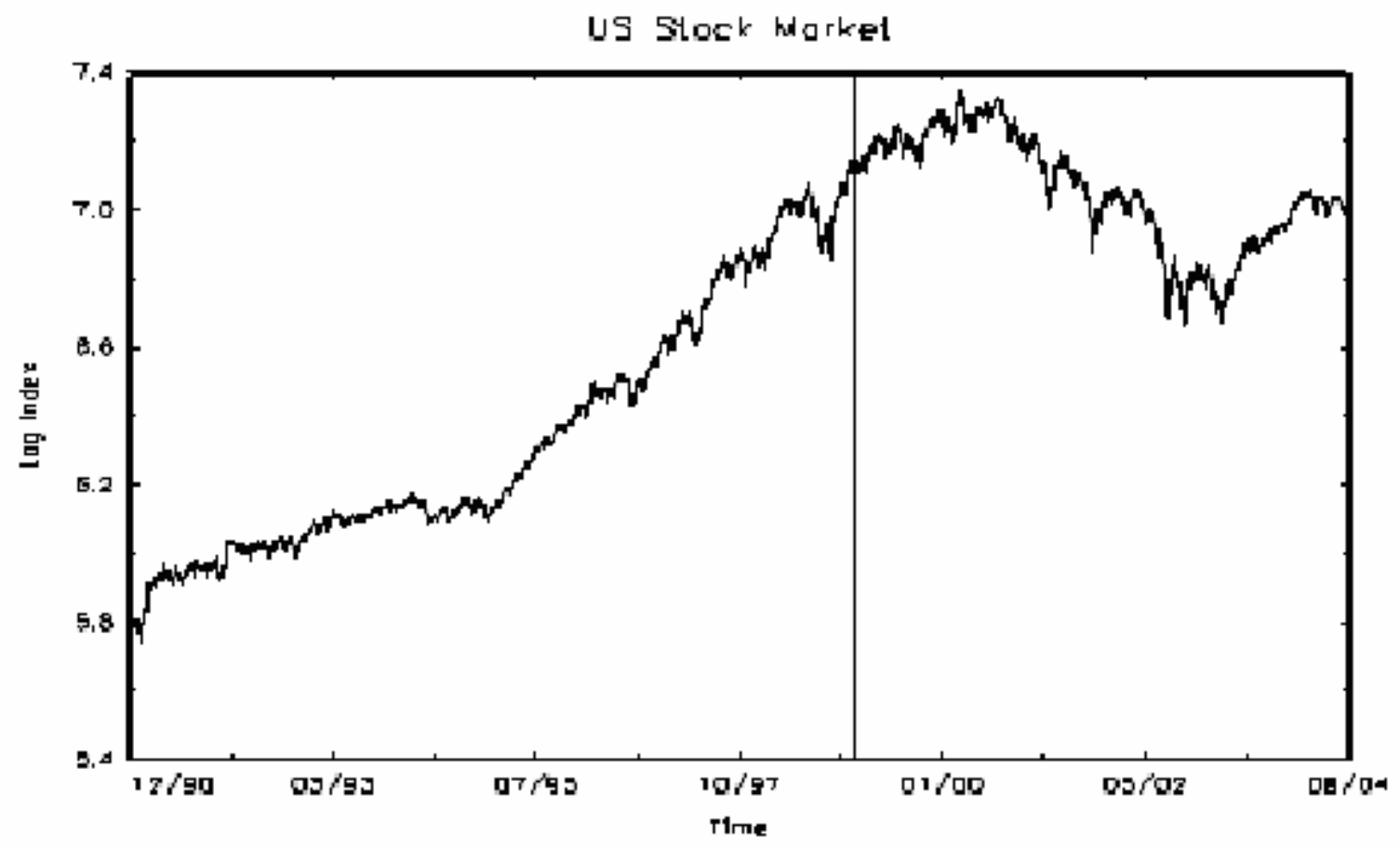

Uk stock kigrket

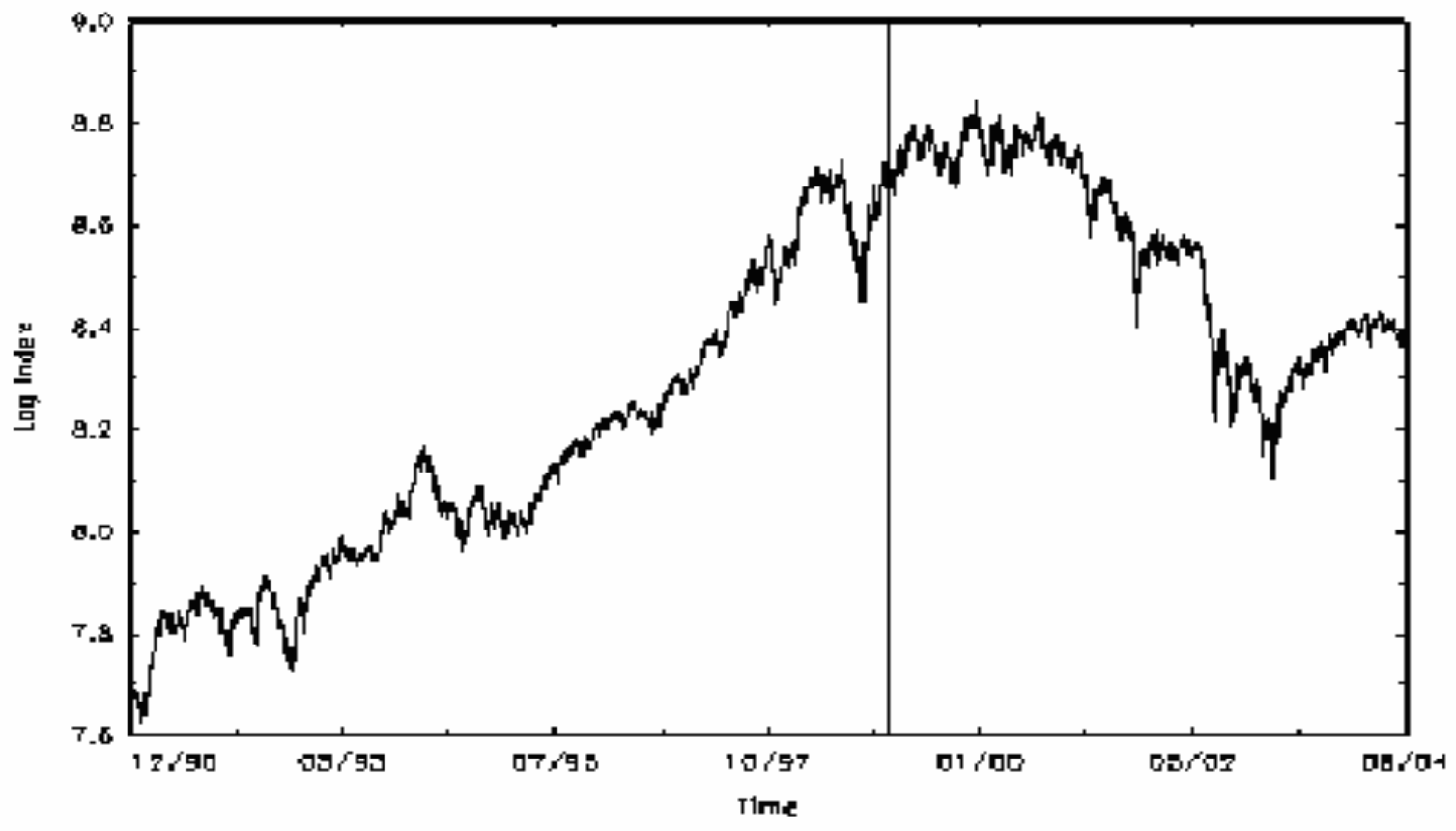



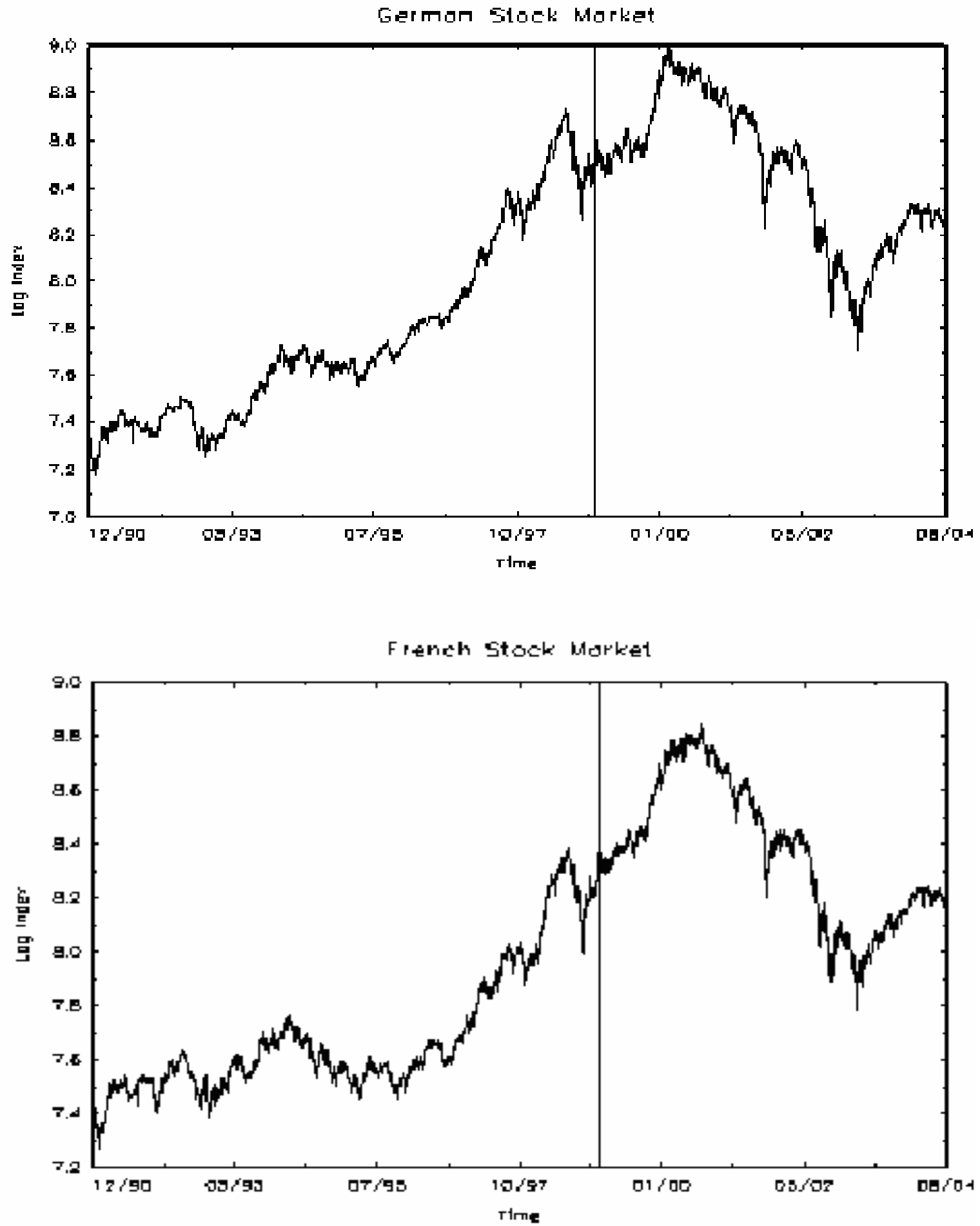
Table 1. Descriptive statistics for daily pseudo closing stock returns

\begin{tabular}{|ccccc|}
\hline & New York & London & Frankfurt & Paris \\
\hline Sample mean & 0.034 & 0.020 & 0.026 & 0.021 \\
& & & & \\
Variance & 1.034 & 1.054 & 2.100 & 1.854 \\
& & & & \\
Kurtosis & $6.263^{* * *}$ & $6.353^{* * *}$ & $7.118^{* * *}$ & $5.805^{* * *}$ \\
& $(0.000)$ & $(0.000)$ & $(0.000)$ & $(0.000)$ \\
Skewness & -0.022 & 0.065 & $-0.337^{* * *}$ & $-0.089^{* *}$ \\
& $(0.299)$ & $(0.056)$ & $(0.000)$ & $(0.016)$ \\
Min & -5.533 & -5.6347 & -9.871 & -7.678 \\
& & & & \\
Max & 5.771 & 6.720 & 7.097 & 7.002 \\
& & & & \\
KS & $0.0735^{* * *}$ & $0.05^{* * *}$ & $0.0491^{* * *}$ & $0.0469^{* * *}$ \\
& $(0.000)$ & $(0.000)$ & $(0.000)$ & $(0.000)$ \\
JB & $1584.85^{* * *}$ & $1674.71^{* * *}$ & $2591.26^{* * *}$ & $1176.32^{* * *}$ \\
& $(0.000)$ & $(0.000)$ & $(0.000)$ & $(0.000)$ \\
LB $(Y ; 12)$ & $22.53^{* *}$ & $58.99^{* * *}$ & $25.76^{* *}$ & $27.731^{* * *}$ \\
LB( $\left.Y_{t}^{2} ; 12\right)$ & $(0.032)$ & $(0.000)$ & $(0.012)$ & $(0.001)$ \\
& $3620.26^{* * *}$ & $4814.50^{* * *}$ & $3763.10^{* * *}$ & $4673.82^{* * *}$ \\
& $(0.000)$ & $(0.000)$ & $(0.000)$ & $(0.000)$ \\
\hline
\end{tabular}

Notes:

Sample period is Dec 31990 to Aug 62004 (3570 days). KS is the Kolmogorov-Smirnov test for normality with $5 \%$ and $1 \%$ critical values equal to $1.36 / \sqrt{ } T$ and $1.63 / \sqrt{ } T$, respectively, for $T$ observations. JB is the Jarque-Bera test for normality (distributed as $\chi^{2}$ with 2 degrees of freedom); $\mathrm{LB}(X ; n)$ is the Ljung-Box statistic for testing autocorrelation up to $n$ lags (distributed as $\chi^{2}$ with $n$ degrees of freedom), calculated for both the returns $\left(X=Y_{t}\right)$ and the squared returns $\left(X=Y_{t}^{2}\right)$. Values in parentheses are $p$-values.

$* *$ denotes significance at the $5 \%$ level.

$* * *$ denote significance at the $1 \%$ level. 


\subsection{The Euro and correlations}

Prior to estimating the AGDCC model, we examine the effects of the Euro in the context of an EGARCH model with constant conditional correlations (CCC), that is, assuming $P$ in (6) is constant over time $e^{4}$. Figure 2 shows the results of possible nested test sequences for testing the existence of breaks in means, variances and correlations. It is clear that the null hypothesis of no breaks is rejected when we test the model with breaks in all terms against the model with no breaks ( LR test $=503.80$ with 14 degrees of freedom, which has a $p$-value of 0.000). An inspection of each sequence of nested hypotheses reveals that the source of overall rejection of the null is due to breaks in the conditional correlations. There is no evidence of breaks in means or volatilities, even at the $10 \%$ level.

The lack of evidence for breaks in volatility at the introduction of the Euro contrasts with the results of Cheung and Westermann (2001) and Billio and Pelizzon (2003). However, neither of these studies separates changes in volatilities and conditional correlations between individual markets, as undertaken here.

Based on the results of Figure 2, we allow structural breaks in the correlation equations only, estimating both CCC and DCC specifications. Table 2 presents results for correlations across markets, using the whole sample period and also the sub-periods before and after the Euro. The table shows the sample correlations for observed returns, together with conditional disturbance correlations estimated from the multivariate EGARCH model with constant conditional correlations (CCC) and average correlations estimated using the AGDCC model. For the CCC and AGDCC results, the model is estimated without allowing

\footnotetext{
${ }^{4}$ The CCC model is used for practical reasons in achieving convergence for estimation of the AGDCC model with structural breaks in the mean, volatility and correlation equations.
} 


\section{Figure 2. Testing for Breaks at the Introduction of the Euro}

Mean/Vol./Corel.

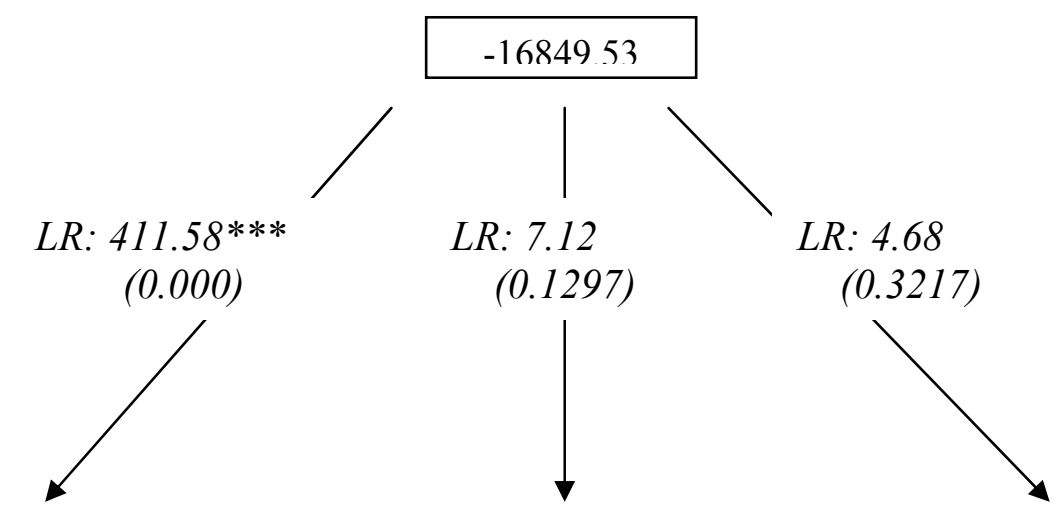

\section{Mean/Vol.}

Mean/Corel.

Vol./Corel.

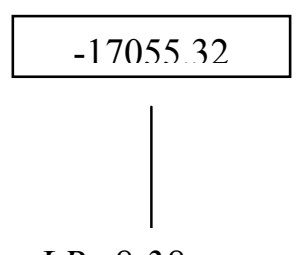

LR: 8.38

(0.079)

$-16853.09$

$-16851.87$

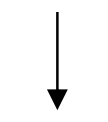

Mean

Correlation

$-17059.51$

$-16855.91$

R: 5.64

(0.228)

LR: $413.18 * * *$

(0.000)
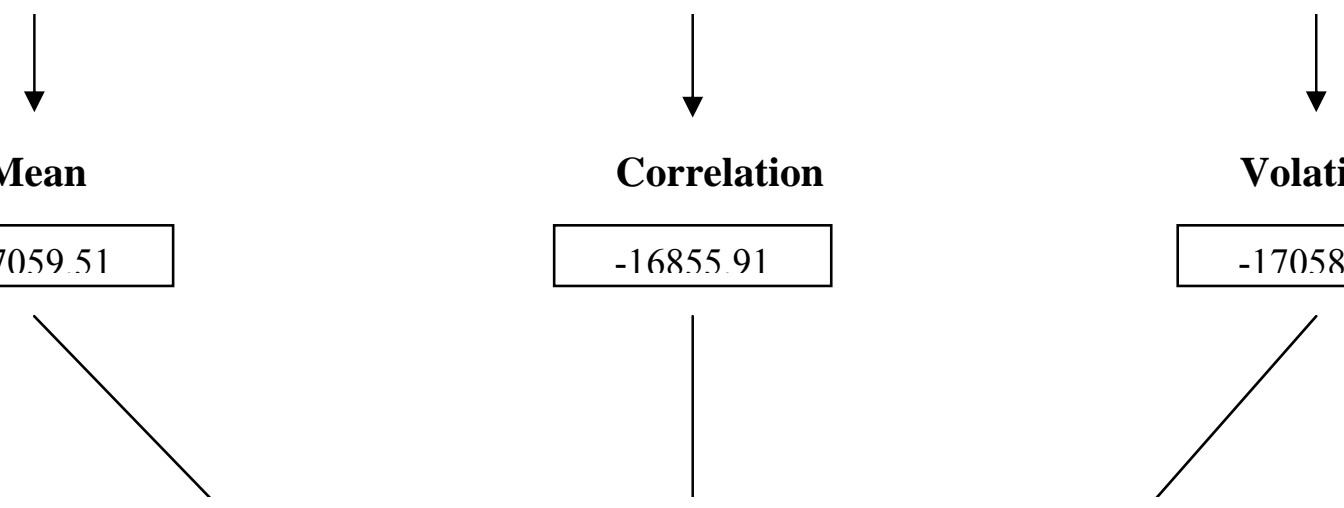

LR: 3.84

$(0.4281)$

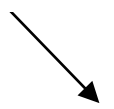

LR: $411.04 * * *$

(0.000)

LR: 5.94

(0.2037)
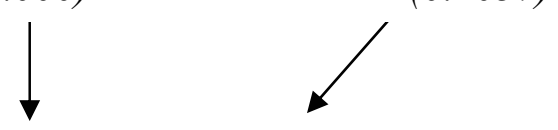

\section{No Breaks}

$-17061.43$

Notes:

The values of the log likelihood function for the Constant Conditional Correlation (CCC) model are shown when estimated with breaks in the mean, volatility and/or correlations at the introduction of the Euro, and with no breaks. Values on the arrows are the likelihood ratio (LR) test statistic for testing the corresponding restrictions, with $p$-values in parentheses. Under the null hypothesis of no break, each LR test statistic is asymptotically distributed as $\chi^{2}$ with the degrees of freedom of 4 when testing means or volatilities, 6 for correlations, 10 for means (or volatilities) and correlations, 8 for means and volatilities, and 14 when testing means, volatility and correlations. 
for a structural break (leading to the results for the complete sample period) and incorporating a structural break in the correlations at the introduction of the Euro (resulting in separate estimates for the pre- and post-Euro periods). That is, for the DCC model, Table 2 compares average conditional correlations using $(7)$ and $\left(7^{\prime}\right)^{5}$.

The broad pattern revealed by the correlations is the same in all three cases. The highest unconditional sample correlations for returns are between Frankfurt and Paris, and London and Paris, both with values around 0.75 over the whole sample. Although the values are a little lower using conditional correlations, these pairs also exhibit the highest correlations between the shocks in the CCC and DCC specifications over the whole period. On the other hand, the lowest correlation over the whole sample is consistently that between Frankfurt and New York.

However, it is clear that these values conceal substantial differences for the periods before and after the Euro. In particular, an increase in the correlations across all markets occurs after the launch of Euro, confirming the analysis of Cappiello et. al. (2003). This increase is most marked between the German and French stock markets. For example, according to the AGDCC model, shocks between these markets have a correlation of 0.85 for the post-Euro period, compared to 0.55 before the Euro. For the same model, the average conditional correlations between the Frankfurt market and each of New York and London increases by 50 percent, while that between Paris and these non-Euro markets increases by less.

The smallest increase in correlations is observed for the New York and London markets, which is compatible with at least some of the effect in other cases being

\footnotetext{
${ }^{5}$ A likelihood ratio test comparing these specifications results in a test statistic of 214.08 , with a $p$-value of 0.0000 , compared to a $\chi^{2}$ distribution with 6 degrees of freedom.
} 
attributable to the Euro, since neither the US or UK is directly involved with the new currency.

It is interesting to note that the relatively low correlation between Frankfurt and New York observed above for the whole sample is particularly associated with the pre-Euro period. After the introduction of the Euro, all three European markets show similar correlations with New York, with this comment applying across all three sets of correlations in Table 2. On the other hand, the strong whole sample correlation between Paris and Frankfurt is largely attributable to the post-Euro period, with the correlation between these markets for the pre-Euro period being substantially less than between London and Paris. 
Table 2. Cross-market correlations

\begin{tabular}{|c|c|c|c|}
\hline & London & Frankfurt & Paris \\
\hline \multirow{4}{*}{$\begin{array}{r}\text { New York (Overall) } \\
\text { (Pre Euro) } \\
\text { (Post Euro) }\end{array}$} & \multicolumn{3}{|c|}{ Sample correlations for returns } \\
\hline & \multirow{9}{*}{$\begin{array}{l}0.6792 \\
06333 \\
0.7127\end{array}$} & 0.6407 & 0.6645 \\
\hline & & 0.5265 & 0.5886 \\
\hline & & 0.7180 & 0.7216 \\
\hline London (Overall) & & 0.6965 & 0.7458 \\
\hline (Pre Euro) & & 0.5737 & 0.6729 \\
\hline (Post Euro) & & 0.7860 & 0.8036 \\
\hline \multirow{3}{*}{$\begin{array}{r}\text { Frankfurt (Overall) } \\
\text { (Pre Euro) } \\
\text { (Post Euro) }\end{array}$} & & & 0.7545 \\
\hline & & & 0.5960 \\
\hline & & & 0.8719 \\
\hline \multirow{4}{*}{$\begin{array}{r}\text { New York (Overall) } \\
\text { (Pre Euro) } \\
\text { (Post Euro) }\end{array}$} & \multicolumn{3}{|c|}{ Constant conditional correlations } \\
\hline & \multirow{9}{*}{$\begin{array}{l}0.6556 \\
0.6178 \\
0.6887\end{array}$} & 0.5888 & 0.6357 \\
\hline & & 0.4899 & 0.5741 \\
\hline & & 0.6882 & 0.6913 \\
\hline London (Overall) & & 0.6270 & 0.7098 \\
\hline (Pre Euro) & & 0.5281 & 0.6544 \\
\hline (Post Euro) & & 0.7287 & 0.7636 \\
\hline \multirow{3}{*}{$\begin{array}{r}\text { Frankfurt (Overall) } \\
\text { (Pre Euro) } \\
\text { (Post Euro) }\end{array}$} & & & 0.7081 \\
\hline & & & 0.5812 \\
\hline & & & 0.8443 \\
\hline \multirow{4}{*}{$\begin{array}{r}\text { New York (Overall) } \\
\text { (Pre Euro) } \\
\text { (Post Euro) }\end{array}$} & \multicolumn{3}{|c|}{ Dynamic conditional correlations (average) } \\
\hline & 0.6436 & 0.5619 & 0.6186 \\
\hline & 0.6008 & 0.4622 & 0.5543 \\
\hline & 0.7053 & 0.7058 & 0.7115 \\
\hline London (Overall) & & 0.5987 & 0.6960 \\
\hline (Pre Euro) & & 0.4991 & 0.6387 \\
\hline (Post Euro) & & 0.7424 & 0.7787 \\
\hline \multirow{3}{*}{$\begin{array}{r}\text { Frankfurt (Overall) } \\
\text { (Pre Euro) } \\
\text { (Post Euro) }\end{array}$} & & & 0.6750 \\
\hline & & & 0.5515 \\
\hline & & & 0.8532 \\
\hline
\end{tabular}

Notes:

For each pair of markets, the first correlation is for the complete sample period ( 3 December 1990 to 6 August 2004), the second is for the pre-Euro period (3 December 1990 to 31 December 1998) and the third for the post-Euro period (1 January 1999 to 6 August 2004). 


\subsection{Price and Volatility Spillovers}

Table 3 presents the estimation results for AGDCC model with structural breaks in the correlations. In terms of first moment interdependencies, there are significant price spillovers from Paris to New York and from New York to Paris. However, although the coefficients have similar values, the effects from Paris are much more significant than the feedback from the US. The result is in line with Martens and Poon (2001), who find significant spillovers from Europe to the US. However, we find no significant effects in either direction between either London or Frankfurt and the US market. Within Europe, Paris has very significant positive spillover effects on London and Frankfurt, but returns in the Frankfurt market have negative impacts on London and Paris. These results, including the magnitudes of the estimated coefficients, point to the leadership role played by Paris for these markets. However, our findings differ from earlier ones of Theodosiou and Lee (1993), Koutmos and Booth (1996), Antoniou et. al. (2003) among others, suggesting that the sample period may be crucial as these relationships may change over time.

Turning to volatility spillovers, it is observed that in addition to own past innovations, the conditional variance in each market is also affected by innovations coming at least from one of the other three markets. Here London plays a key role, being significant at less than 1 percent for all other markets, including New York. However, there are no significant volatility spillovers from New York to any other market. Previous studies document feedback effects in conditional volatility for London and New York markets (for instance see the results of Koutmos and Booth (1995), Veiga and McAleer (2003)), with our 
different finding suggesting that ignoring the time lag between US and Europe might be important an important reason behind these earlier results ${ }^{6}$.

However, the volatility results may also be due partly to the different times within the trading day represented by our use of pseudo-closing prices. Various studies (such as Chan et. al. (1991), Engle et. al. (1994), Andersen (2000) among others) show that the volatility in US stock market is higher during opening and closing periods. Our pseudo closing prices, taken at 16:00 London time, correspond to 17.00 in Paris and Frankfurt, but to 11:00 in New York, when the S\&P500 volatility reaches its lowest level (U shape of volatility $)^{7}$

Within Europe, in addition to the spillover effects from London, we find unidirectional volatility spillovers occur from Frankfurt to Paris and from Paris to London, with the latter being highly significant. The different leadership roles within the mean and volatility equations should be noted, with Paris the key market for the former and London for the latter.

Table 3 also shows the volatility transmission mechanism to be asymmetric for all markets. That is, the coefficients measuring asymmetry, namely $\gamma_{j}$ in (3), are significant for all four markets; reinforcing the assertion that bad news increases volatility more than good news. The size of these asymmetries can be assessed using the estimated coefficients. Thus, a negative innovation in New York, London, Frankfurt and Paris is estimated to increase volatility in each market by $3.47,3.73,1.98$ and 3.60 times, respectively, that of a positive innovation of the same magnitude.

\footnotetext{
6 When applied the model is estimated using closing prices, the results suggest somewhat different interdependencies.

${ }^{7}$ We are grateful to Maria Kasch-Haroutounian for drawing our attention to this point.
} 
Table 3. Estimated asymmetric DCC model

\begin{tabular}{|c|c|c|c|c|c|c|c|}
\hline \multicolumn{2}{|c|}{\begin{tabular}{|c|} 
New York \\
\end{tabular}} & \multicolumn{2}{|c|}{ London } & \multicolumn{2}{|c|}{ Frankfurt } & \multicolumn{2}{|r|}{ Paris } \\
\hline \multicolumn{8}{|c|}{ Returns equations } \\
\hline$\beta_{1,0}$ & $\begin{array}{l}0.03370 \text { *** } \\
{[0.013]} \\
(0.0043)\end{array}$ & $\beta_{2,0}$ & $\begin{array}{l}0.01960 * \\
{[0.013]} \\
(0.0688)\end{array}$ & $\beta_{3,0}$ & $\begin{array}{l}0.0333 \text { ** } \\
{[0.017]} \\
(0.02647) \\
\end{array}$ & $\beta_{4,0}$ & $\begin{array}{l}0.0303 * * \\
{[0.017]} \\
(0.03825) \\
\end{array}$ \\
\hline$\beta_{1,1}$ & $\begin{array}{l}-0.0702 * * * \\
{[0.022]} \\
(0.0006)\end{array}$ & $\beta_{2,1}$ & $\begin{array}{l}0.00380 \\
{[0.021]} \\
(0.4279)\end{array}$ & $\beta_{3,1}$ & $\begin{array}{l}0.03340 \\
{[0.027]} \\
(0.1072)\end{array}$ & $\beta_{4,1}$ & $\begin{array}{l}0.04310 * * \\
{[0.025]} \\
(0.04240)\end{array}$ \\
\hline$\beta_{1,2}$ & $\begin{array}{l}-0.00590 \\
{[0.022]} \\
(0.3929)\end{array}$ & $\beta_{2,2}$ & $\begin{array}{l}0.01660 \\
{[0.021]} \\
(0.2135)\end{array}$ & $\beta_{3,2}$ & $\begin{array}{l}0.05280 * * \\
{[0.028]} \\
(0.02925)\end{array}$ & $\beta_{4,2}$ & $\begin{array}{l}-0.0033 \\
{[0.028]} \\
(0.4529)\end{array}$ \\
\hline$\beta_{1,3}$ & $\begin{array}{l}-0.01000 \\
{[0.018]} \\
(0.2871)\end{array}$ & $\beta_{2,3}$ & $\begin{array}{l}-0.0594 * * * \\
{[0.018]} \\
(0.0006)\end{array}$ & $\beta_{3,3}$ & $\begin{array}{l}-0.1854 \text { *** } \\
{[0.024]} \\
(0.0000)\end{array}$ & $\beta_{4,3}$ & $\begin{array}{l}-0.0794 * * * \\
{[0.024]} \\
(0.00055)\end{array}$ \\
\hline$\beta_{1,4}$ & $\begin{array}{l}0.04980 * * * \\
{[0.017]} \\
(0.0021)\end{array}$ & $\beta_{2,4}$ & $\begin{array}{l}0.0655 * * * \\
{[0.018]} \\
(0.00014)\end{array}$ & $\beta_{3,4}$ & $\begin{array}{l}0.2145 * * * \\
{[0.024]} \\
(0.0000)\end{array}$ & $\beta_{4,4}$ & $\begin{array}{l}0.04560 \text { ** } \\
{[0.024]} \\
(0.02824)\end{array}$ \\
\hline \multicolumn{8}{|c|}{ Volatility equations } \\
\hline$\alpha_{1,0}$ & $\begin{array}{l}0.00001 \\
{[0.0013]} \\
(0.5000)\end{array}$ & $\alpha_{2,0}$ & $\begin{array}{l}-0.0021 * * \\
{[0.0012]} \\
(0.0401)\end{array}$ & $\alpha_{3,0}$ & $\begin{array}{l}0.0083 * * * \\
{[0.0016]} \\
(0.0000)\end{array}$ & $\alpha_{4,0}$ & $\begin{array}{l}0.0098 * * * \\
{[0.0016]} \\
(0.0000)\end{array}$ \\
\hline$\alpha_{1,1}$ & $\begin{array}{l}0.07130 * * * \\
{[0.0087]} \\
(0.0000)\end{array}$ & $\alpha_{2,1}$ & $\begin{array}{l}0.00460 \\
{[0.0077]} \\
(0.2751)\end{array}$ & $\alpha_{3,1}$ & $\begin{array}{l}-0.00080 \\
{[0.0079]} \\
(0.4597)\end{array}$ & $\alpha_{4,1}$ & $\begin{array}{l}-0.0047 \\
{[0.0076]} \\
(0.2682)\end{array}$ \\
\hline$\alpha_{1,2}$ & $\begin{array}{l}0.03000 * * * \\
{[0.0094]} \\
(0.0007)\end{array}$ & $\alpha_{2,2}$ & $\begin{array}{l}0.0579 * * * \\
{[0.0095]} \\
(0.0000)\end{array}$ & $\alpha_{3,2}$ & $\begin{array}{l}0.0251 * * * \\
{[0.0096]} \\
(0.00449) \\
\end{array}$ & $\alpha_{4,2}$ & $\begin{array}{l}0.02080 \text { *** } \\
{[0.0085]} \\
(0.00723)\end{array}$ \\
\hline$\alpha_{1,3}$ & $\begin{array}{l}-0.00070 \\
{[0.0096]} \\
(0.4709)\end{array}$ & $\alpha_{2,3}$ & $\begin{array}{l}0.00200 \\
{[0.0099]} \\
(0.4200)\end{array}$ & $\alpha_{3,3}$ & $\begin{array}{l}0.0690 * * * \\
{[0.012]} \\
(0.0000)\end{array}$ & $\alpha_{4,3}$ & $\begin{array}{l}0.02100 \text { ** } \\
{[0.010]} \\
(0.01790)\end{array}$ \\
\hline$\alpha_{1,4}$ & $\begin{array}{l}0.01550 * \\
{[0.010]} \\
(0.0625)\end{array}$ & $\alpha_{2,4}$ & $\begin{array}{l}0.0442 * * * \\
{[0.012]} \\
(0.0000)\end{array}$ & $\alpha_{3,4}$ & $\begin{array}{l}0.00950 \\
{[0.011]} \\
(0.1851) \\
\end{array}$ & $\alpha_{4,4}$ & $\begin{array}{l}0.05880 \text { *** } \\
{[0.011]} \\
(0.0000)\end{array}$ \\
\hline$\gamma_{1}$ & $\begin{array}{l}-0.5529 * * * \\
{[0.1090]} \\
(0.0000)\end{array}$ & $\gamma_{2}$ & $\begin{array}{l}-0.5772 * * * \\
{[0.15]} \\
(0.0000)\end{array}$ & $\gamma_{3}$ & $\begin{array}{l}-0.3281 * * * \\
{[0.082]} \\
(0.0000)\end{array}$ & $\gamma_{4}$ & $\begin{array}{l}-0.5650 * * * \\
{[0.12]} \\
(0.0000)\end{array}$ \\
\hline$\delta_{1}$ & $\begin{array}{l}0.9849 * * * \\
{[0.0020]} \\
(0.0000)\end{array}$ & $\delta_{2}$ & $\begin{array}{l}0.9844 * * * \\
{[0.0020]} \\
(0.0000) \\
\end{array}$ & $\delta_{3}$ & $\begin{array}{l}0.9857 \text { *** } \\
{[0.0020]} \\
(0.0000)\end{array}$ & $\delta_{4}$ & $\begin{array}{l}0.9847 * * * \\
{[0.0021]} \\
(0.0000)\end{array}$ \\
\hline
\end{tabular}




\begin{tabular}{|c|c|c|c|c|}
\hline \multicolumn{5}{|c|}{$\begin{array}{l}\text { Table } 3 \text { (continued) } \\
\text { Conditional correlations }\end{array}$} \\
\hline (2) & New York & London & Frankfurt & Paris \\
\hline$a_{j j}$ & $\begin{array}{l}0.1162 * * * \\
{[0.014]} \\
(0.0000)\end{array}$ & $\begin{array}{l}0.1349 * * * \\
{[0.019]} \\
(0.0000)\end{array}$ & $\begin{array}{l}0.1462 * * * \\
{[0.019]} \\
(0.0000)\end{array}$ & $\begin{array}{l}0.1970 * * * \\
{[0.015]} \\
(0.0000)\end{array}$ \\
\hline$b_{j j}$ & $\begin{array}{l}0.9818 * * * \\
{[0.0058]} \\
(0.0000)\end{array}$ & $\begin{array}{l}0.9649 * * * \\
{[0.0077]} \\
(0.0000)\end{array}$ & $\begin{array}{l}0.9719^{* * *} \\
{[0.0068]} \\
(0.0000)\end{array}$ & $\begin{array}{l}0.9691 * * * \\
{[0.0048]} \\
(0.0000)\end{array}$ \\
\hline$c_{j j}$ & $\begin{array}{l}0.07480 * * * \\
{[0.023]} \\
(0.00055)\end{array}$ & $\begin{array}{l}0.1541 * * * \\
{[0.034]} \\
(0.0000)\end{array}$ & $\begin{array}{l}0.1171 * * * \\
{[0.028]} \\
(0.0000)\end{array}$ & $\begin{array}{l}0.05870 * * \\
{[0.029]} \\
(0.02297)\end{array}$ \\
\hline
\end{tabular}

\begin{tabular}{|c|c|c|c|c|}
\hline Diagnostics & \multicolumn{5}{|c|}{} \\
\hline$E(z)$ & -0.0036 & 0.00025 & -0.00048 & -0.01199 \\
\hline$E\left(z^{2}\right)$ & 0.992 & 1.058 & 1.011 & 0.967 \\
\hline KS & $0.0376^{* * *}$ & 0.0202 & $0.0341^{* * *}$ & $0.0268^{* *}$ \\
\hline JB & $467.07^{* * *}$ & $827.72^{* * *}$ & $2273.37^{* * *}$ & $1165.42^{* * *}$ \\
\hline$L B(z ; 12)$ & 12.67 & 14.98 & 12.49 & 19.49 \\
\hline$L B\left(z^{2} ; 12\right)$ & 3.65 & 9.73 & 5.03 & 7.84 \\
\hline$M L B\left(z^{2} ; 12\right)$ & \multicolumn{5}{|c|}{112.34} \\
\hline Log-likelihood & \multicolumn{5}{|c|}{} \\
\hline
\end{tabular}

\section{Notes:}

The asymmetric DCC model is estimated allowing for a structural break in the conditional correlations. QML standard errors are reported in square brackets while p-values are in brackets. The sample period is Dec 31990 to Aug 62004 (3570 days). $E(z)$ and $E\left(z^{2}\right)$ are the sample mean and sample variance of the standardized residuals. KS is the Kolmogorov-Smirnov test for normality, with $5 \%$ and $1 \%$ critical values equal to $1.36 / \sqrt{ } T$ and $1.63 / \sqrt{ } T$ respectively for $T$ observations, JB is the Jarque-Bera test for normality (distributed as $\chi^{2}$ with 2 degrees of freedom), both computed using the standardized residuals. $\operatorname{LB}(X ; n)$ is the Ljung-Box statistic for testing autocorrelation up to $n$ lags (distributed as $\chi^{2}$ with $n$ degrees of freedom), calculated for both the standardized residuals $\left(X=z_{j, t}\right)$ and the squared normalized residuals $\left(X=z_{j, t}{ }^{2}\right)$. MLB refers to the multivariate version of the Ljung-Box statistic.

$* *$ denotes significance at the $5 \%$ level.

*** denote significance at the $1 \%$ level. 


\subsection{Dynamic conditional correlations}

In addition to the higher conditional volatility induced negative innovations compared with positive ones (discussed in the previous subsection), our results imply they also induce stronger co-movements. This effect in the conditional correlations, captured by the coefficients $c_{j j}$ of (7') with estimates in Table 3, occurs across each of the four markets, but is least significant in the case of the Paris market. A likelihood ratio test resoundly rejects the null hypothesis of no asymmetry in the dynamic conditional correlations. The finding of higher correlations for negative shocks is in line with other results in the literature (for instance see Longin and Solnik (1998), Cappiello et. al. (2003), Martens and Poon (2001), etc).

The conditional correlations also exhibit high persistence, with coefficients varying from 0.965 to $0.982^{8}$. Nevertheless, the most recent return co-movement, captured by the $\operatorname{term} z_{t-1} z_{t-1}$ ', also carries relatively large weight as the estimated $a_{j j}$ coefficient estimates are highly significant for all markets.

The asymmetric response of correlations to joint shocks in two markets can be illustrated using news impact surfaces. The news impact surface for the correlation implied by (7) is given by

$$
\begin{array}{llrl}
f\left(z_{i}, z_{j}\right) \approx \bar{q}_{i j}+\left(a_{i} a_{j}+c_{i} c_{j}\right) z_{i} z_{j}, & & \text { for } z_{i}, z_{j}<0 \\
f\left(z_{i}, z_{j}\right) \approx \bar{q}_{i j}+a_{i} a_{j} z_{i} z_{j}, & & \text { otherwise }
\end{array}
$$

where $z_{i}, z_{j}$ are standardized residuals for markets $i$ and $j$, and $\bar{q}_{i j}$ is the corresponding element of $\bar{Q}$. These effects are illustrated in Figure 3, which graphically presents the impact of different combinations of standardized residuals on the correlation of shocks

\footnotetext{
${ }^{8}$ The condition for positive definiteness, discussed above in relation to ( $\left.7^{\prime}\right)$, has been checked and it is satisfied for the estimated matrices A, B and C.
} 
between the Paris and London stock markets. Both markets play important role in price and volatility spillovers respectively. It is clear that negative shocks in both markets have greater impact on the correlation than positive shocks. Nevertheless, the shocks induced by combinations of same signs have greater impact than other combinations. This pattern is characteristic and applies for the remaining combinations of markets.

\section{Figure 3. News Impact Surfaces}

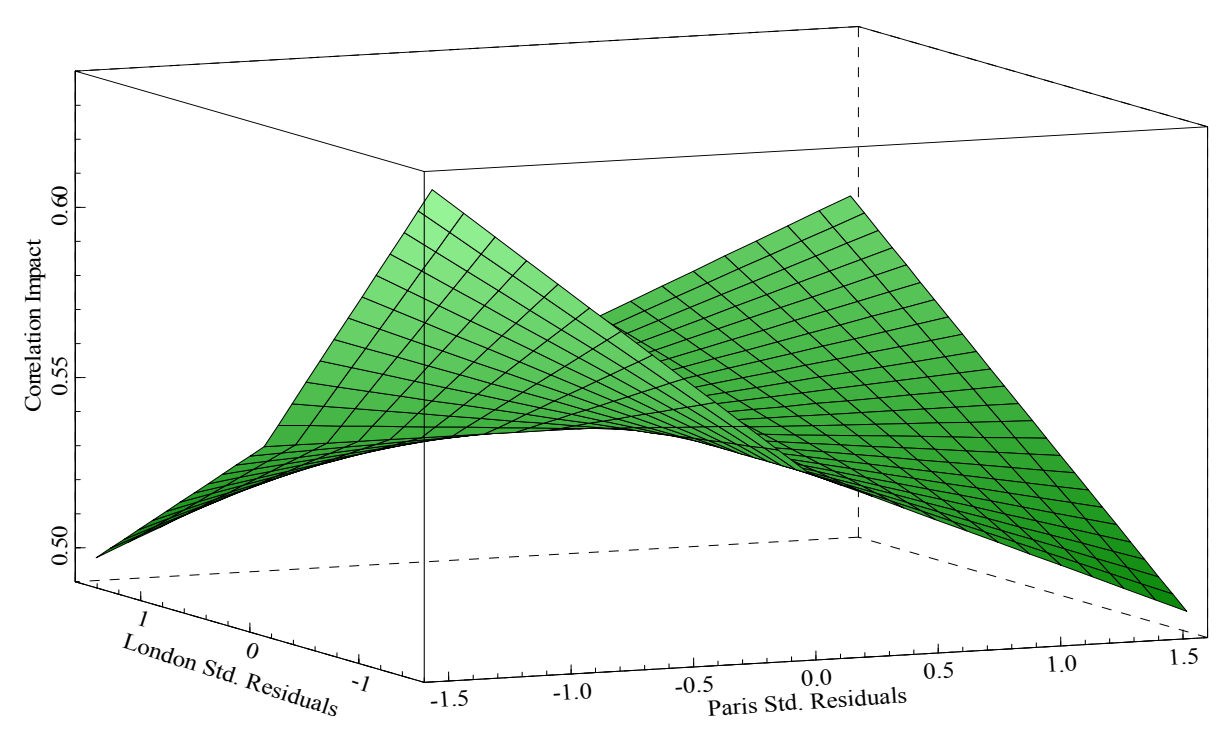

The dynamic conditional correlations captured in (7') are plotted in Figure 4. Given the results in Table 2, it is not surprising that these daily conditional correlations trend upwards over time, with the most pronounced increase being between the German and French stock markets.

Perhaps the most remarkable implication of Figure 4 relates to the stability in the dynamic conditional correlation between these markets over the post-Euro period. From around 2001, the correlation has not only remained high (around 0.9), but it is substantially less volatile than in the preceding period. Although the daily correlations between the US and UK markets increase over the period, there is no compelling visual evidence of a change 
in the volatility of these correlations. On the other hand, with the exception of a small number of sharp and brief declines, there is also evidence of increased stability in the correlations between the US or the UK and the French/German markets, which may be an effect of the Euro reducing some of the currency risks across these markets.

Finally, Figure 5 presents a scatter plot of the estimated conditional correlations against the volatility of the underlying markets. All the plots are very similar to the one below (we plot the graph of the conditional correlation between FTSE100 and CAC40 against the conditional volatility of FTSE100). The interesting feature we note is that extreme volatilities are associated with high correlations. This result agrees with the findings of Kasch-Haroutounian (2005), giving indirect verification to the assertion that negative shocks lead to higher volatilities and consequently higher correlations. 
Figure 4. Daily Dynamic Conditional Correlations
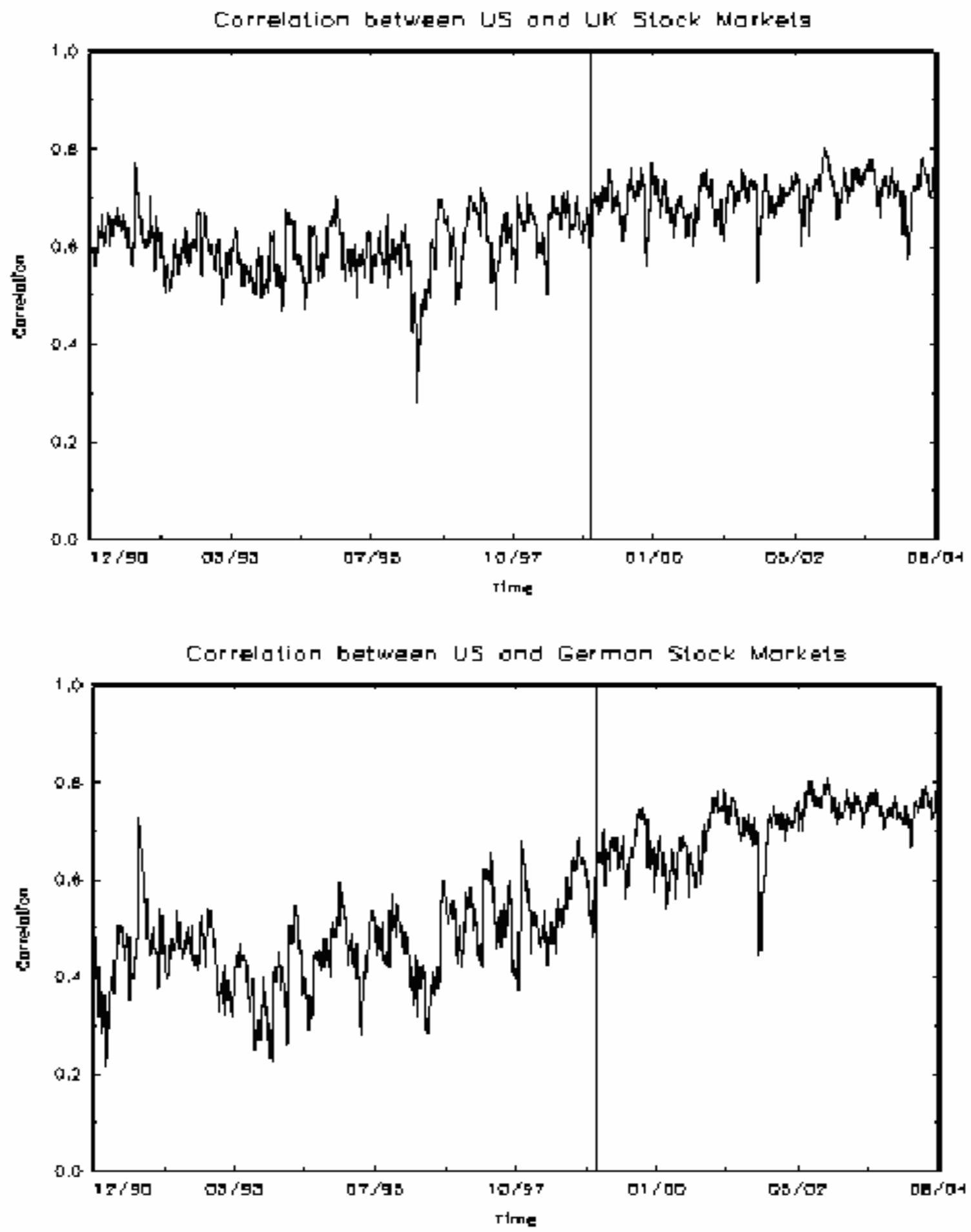

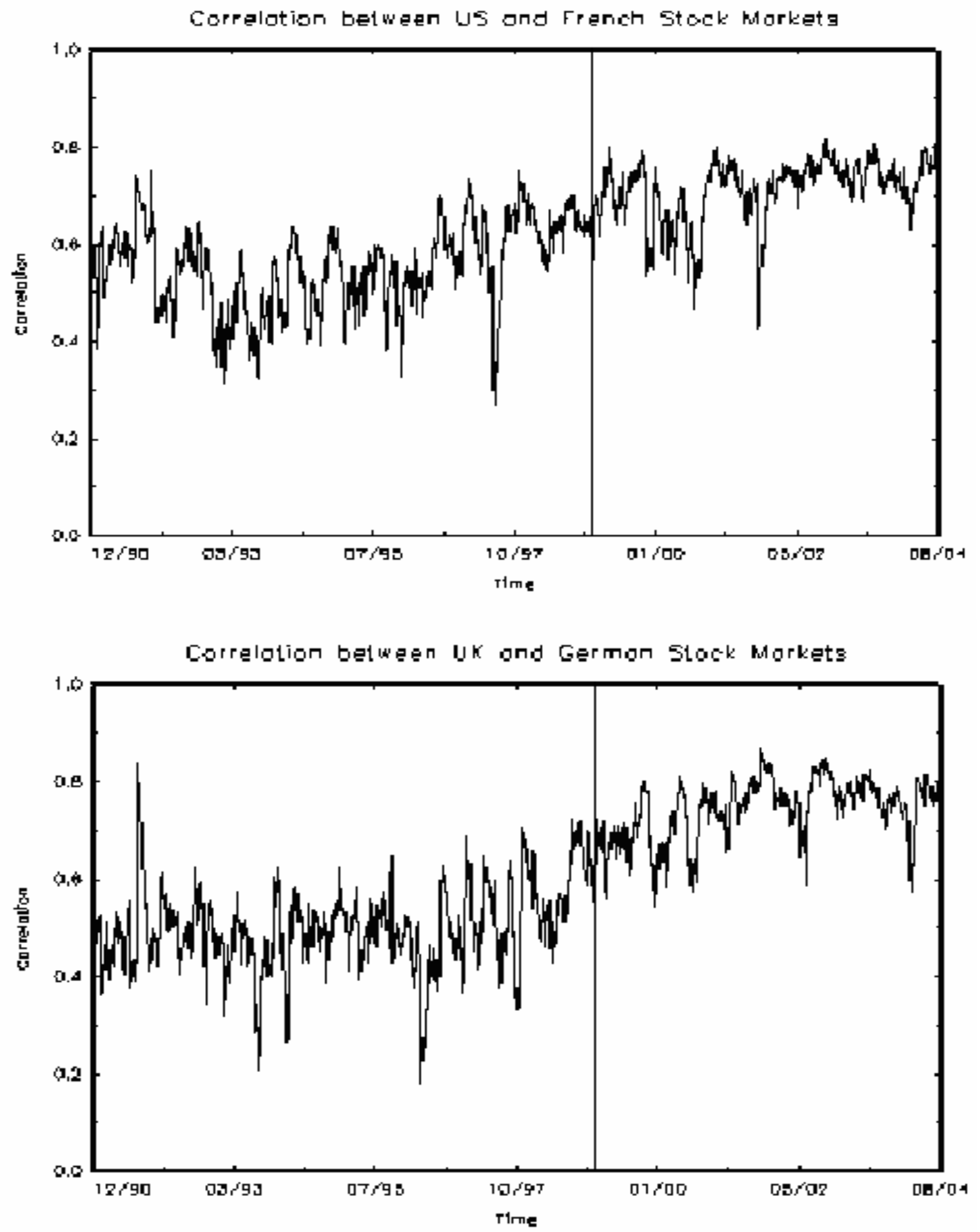

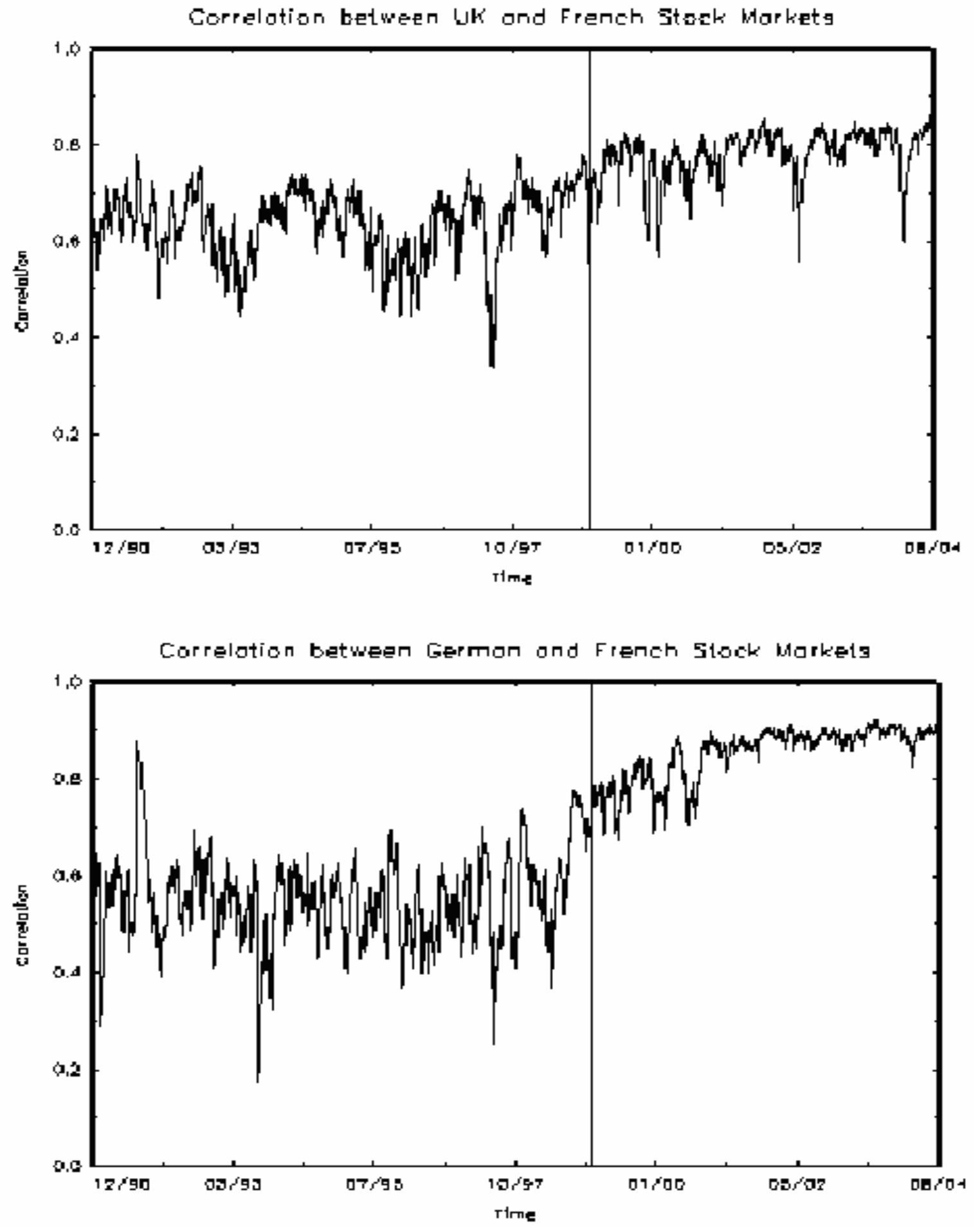
Figure 5. Scatter Plots between Volatility and Conditional Correlations

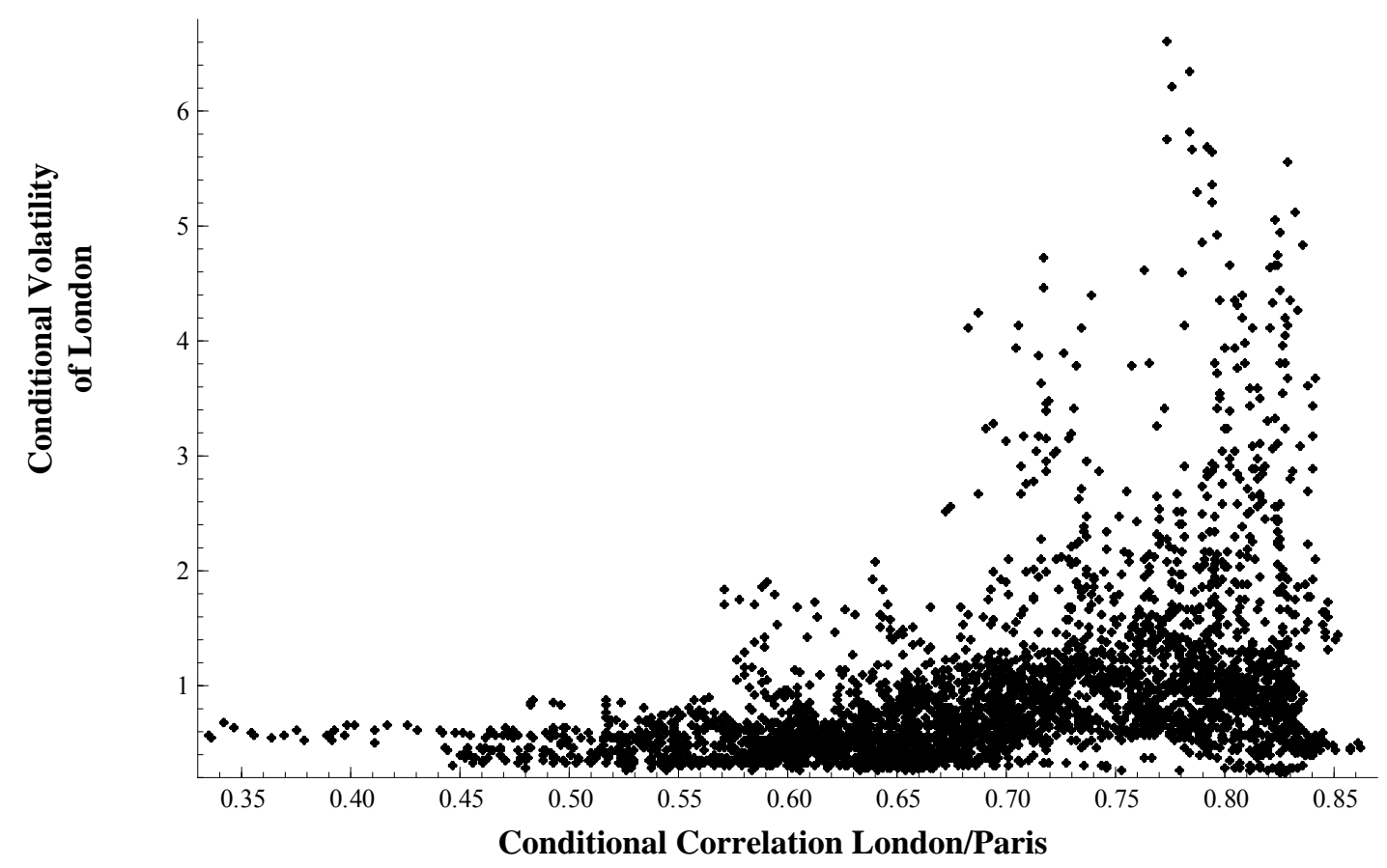

\section{Summary and Conclusions}

This paper estimates an asymmetric dynamic conditional correlation version of the Multivariate EGARCH model for daily stock market returns for four major world markets, namely New York, London, Frankfurt and Paris, reflecting the outlook of American and European investors. We employ pseudo-closing prices, in order to avoid the problem of non-synchronous closing times. Further, we also investigate the effect of the introduction of the common Euro currency on the correlations of shocks across these markets.

The results provide evidence that both domestic stock prices and their volatilities are influenced by the behavior of foreign markets. We find that the Paris stock market acts as an information producer for the period under investigation (December 1990 to August 2004). It has price spillovers effects to each of the other markets, while the London market has 
volatility spillover effects to the other markets. Further, we find that volatility responds asymmetrically to news/innovations in other markets, with a stronger response in the case of bad news than good news. The importance of asymmetries is emphasized by the news impact surface, which shows higher correlations when negative shocks occur in both markets than in other cases.

One of the major goals of this paper is to examine the effects of the Euro on correlations between markets, with the results evidencing a significant increase since the introduction of the new currency. While this increase is not confined to the Euro Area markets of Paris and Frankfurt, the increase is most marked for the correlation between these markets. Indeed, we find that the correlation of shocks for these two markets is not only high (at around 0.9 ), but is remarkably constant for the period since 2001. Indeed, in contrast to earlier studies, we find that the important effects of the Euro are on the conditional correlations, rather than on mean or volatility relationships. 


\section{REFERENCES}

Antoniou, A., Pescetto, G., and Violaris, A., 2003. Modelling International Price Relationships and Interdependencies Between the Stock Index Future Markets of Three EU Countries: A Multivariate Analysis. Jounal of Business \& Accounting 30, 645-667.

Baele, L. (forthcoming). Volatility Spillover Effects in European Equity Markets: Evidence form a Regime Switching Model. Journal of Financial and Quantitative Analysis.

Billio, M. and L. Pelizzon, 2003. Volatility and Shocks Spillover Before and After EMU in European Stock Markets. Journal of Multinational Financial Management 13, 323340.

Bollerslev, T., 1990. Modelling the Coherence in Short-Run Nominal Exchange Rates: A Multivariate Generalized Arch Model. Review of Economics and Statistics 72, 498505.

Cappiello, L., Robert, E., \& Sheppard, K., 2003. Asymmetric Dynamics in the Correlation of Global Equity and Bond Returns. European Central Bank, Working Paper Series, No. 204.

Cheung, Y.-W. and F. Westermann, 2001. Equity Price Dynamics Before and After the Introduction of the Euro. Multinational Finance Journal 5, 113-128

Christiansen, C., 2003. Volatiliy-Spillover Effects in European Bond Markets. Working Paper, Aarhus School of Business.

Christiansen, C., 2005. Decomposing European Bond and Equity Voaltility. Working Paper, Aarhus School of Business.

Engle, R., 1990. Discussion: Stock Volatility and the Crash of '87. Review of Financial Studies 3, 103-106.

Engle, R., 2002. Dynamic Conditional Correlation - A Simple Class of Multivariate GARCH Models. Journal of Business and Economic Statistics 20, 339-350.

Engle, R., and Ng, V. K., 1993. Measuring and Testing the Impact of News on Volatility. Journal of Finance 48, 1749-1778.

Franses, P. H. and C. M. Hafner, 2003. A Generalised Dynamic Conditional Correlation Model for Many Asset Returns, Econometric Institute Report EI 2003-18, Erasmus University Rotterdam. 
Grubel, H. G., 1968. Internationally Diversified Portfolios: Welfare Gains and Capital Flows. American Economic Review 58, 1299-1314.

Hamao, Y. R., Masulis, R. W., and Ng, V. K., 1990. Correlation in Price Changes and Volatility Across International Stock Markets. The Review of Financial Studies 3, 281-307.

Kasch-Haroutounian, M,. 2005. Volatility Threshold Dynamic Conditional Correlations: Implications for International Portfolio Diversification. Presented at the Journal of Applied Econometrics Conference on "Changing Structures in International and Financial Markets and the Effects on Financial Decision Making", Venice, Italy, June 2-3, 2005.

Kim, S., F. Moshirian, and Wu, E.. (forthcoming). Dynamic Stock Market Integration Driven by the European Monetary Union: An Empirical Analysis. Journal of Banking and Finance.

Koutmos, G., and Booth, G., 1995. Asymmetric Volatility Transmission in International Stock Markets. Journal of International Money and Finance 14, 747-762.

Koutmos, G., 1996. Modeling the Dynamic Interdependence of Major European Stock Markets. Journal of Business Finance and Accounting 23, 975-988.

Lastrapes, W. D., 1989. Exchange Rate Volatility and US Monetary Policy: An ARCH Application. Journal of Money Credit and Banking 21, 66-77.

Longin, F., Solnik, B., 2001. Extreme Correlation of International Equity Markets. Journal of Finance 56, 649-676.

Martens, M., and Poon S., 2001. Returns Synchronization and Daily Correlation Dynamics Between International Stock Markets. Journal of Banking and Finance 25, 18051827.

Melle M., 2003. The EURO Effect on the Integration of European Stock Markets. Retrieved from http://xiforofinanzas.ua.es/trabajos/1027.pdf.

Nelson, D. B., 1991. Conditional Heteroskedasticity in Asset Returns: A New Approach. Econometrica 59, 347-370.

Rehman, S., 2002. Euro Changeover Costs for International Banks. International Finance 2, 27-42.

Taylor, S., Bartram, S. and Wang Y., 2005. The Euro and European Financial Market Intergration. Presented at Journal of Applied Econometrics Conference on 
"Changing Structures in International and Financial Markets and the Effects on Financial Decision Making", Venice, Italy, June 2-3, 2005.

Theodosiou, P., and Lee, U., 1993. Mean and Volatility Spillovers Across Major National Markets: Further Empirical Evidence. Journal of Financial Research 16, 337-350.

Tse, Y. K., 2000. A Test for Constant Correlations in a Multivariate GARCH Model. Journal of Econometrics 98, 107-127.

Van Dijk, D., Munandar, H. and Hafner, C., 2005, The Euro Introduction and Non-Euro Currencies. Presented at Journal of Applied Econometrics Conference on "Changing Structures in International and Financial Markets and the Effects on Financial Decision Making", Venice, Italy, June 2-3, 2005.

Veiga, B., and McAleer, M., 2003. Multivariate Volatility and Spillover Effects in Financial Markets. http://www.iemss.org/iemss2004/pdf/risk/veigmult.pdf 1-7.

Wong, A.S.K and Vlaar P.J.G., 2003. Modelling Time-Varying correlations of Financial Markets. Retrieved from $h t t p: / / w w w . d n b . n l / d n b / b i n / d o c / w o 0739$ tcm13-35913.pdf. 